\title{
El motivo de Ofelia en la lírica expresionista alemana: denuncia social, política y marginalidad
}

\author{
Ana Rubio Jiménez \\ Universidad de Córdoba \\ anamariarj96@gmail.com \\ https://dx.doi.org.10.12795/futhark.2020.il5.1I
}

Fecha de recepción: 10.02 .2020

Fecha de aceptación: 30.05 .2020

Resumen: El trágico motivo de Ofelia ha sido utilizado para transmitir diversos mensajes en la lírica expresionista alemana. Poetas como Georg Heym, Gottfried Benn, Bertolt Brecht y Peter Huchel han utilizado a Ofelia como vehículo para expresar su descontento con la sociedad del momento y como arma de denuncia social y política. El propósito de este artículo es exponer y analizar los principales poemas en los que aparece esta figura.

Palabras clave: lírica, expresionismo, Ofelia, literatura alemana, denuncia social, marginal.

\section{Ophelia's Motif in German expressionist Lyric Poetry: social Denunciation, Politics and Marginalization}

\begin{abstract}
Ophelia's tragic motif has been used in German expressionist lyric poetry to convey diverse messages. Poets such as Georg Heym, Gottfried Benn, Bertolt Brecht and Peter Huchel have used the young Ophelia as a vehicle to express their discontent with society and as a tool for social and political denunciation. The purpose of this article is to expose and analyse the main poems in which this figure appears.
\end{abstract}

Keywords: lyrical poetry, expressionism, Ophelia, German literature, social denunciation, marginal. 
Sumario: Introducción. I. Antecedentes. I.I. Ophélie de Arthur Rimbaud. 2. La lírica expresionista alemana. 2.I. Ophelia de Georg Heym. 2.2. Schöne Jugend de Gottfried Benn. 3. Ofelia y lo politico. 3.I. Bertolt Brecht: Ofelia y el asesinato de Rosa Luxemburg. 3.2. El motivo politico en Ophelia de Peter Huchel. Conclusiones.

\section{Introducción}

El motivo de la muerte de Ofelia, llamado “die Schöne Wasserleiche” (el hermoso cadáver encontrado en el agua) en la lírica expresionista alemana, es un tema recurrente en la literatura ${ }^{1} y$ otras $\operatorname{artes}^{2}$ que se ha reproducido a lo largo de los siglos y con diversos fines. Multitud de autores se han valido del simbolismo que rodea a la figura de Ofelia para usarla como medio de crítica social y política a través de la literatura.

Ofelia es un personaje trágico de la obra Hamlet, del famoso dramaturgo Shakespeare. Su papel es el de la joven dama casta, presionada por las convecciones sociales, que enloquece tras ser abandonada por su amor y que termina su vida arrojándose al río.

El suicidio de Ofelia es el final drástico, por tanto, de una mujer joven que se encuentran en un profundo enfrentamiento entre la moral de su época, que se presenta hostil e hipócrita, y sus propios deseos. La muerte trae paz al cadáver de Ofelia, que se une a la naturaleza; la imagen de Ofelia, de su huida de una realidad impregnada de sufrimiento y decadencia, que transforma a una muchacha tremendamente apesadumbrada y trastornada en parte de la naturaleza, en una calma eterna, fue utilizada por la lírica expresionista del siglo $X X$ para servir de nueva concepción de mujer, naturaleza y civilización.

En el presente trabajo pretendo exponer y analizar los poemas de Georg Heym, Gottfried Benn, Bertolt Brecht y Peter Huchel, que utilizan este motivo de Ofelia y que podríamos considerar marginales por la estética feísta que poseen, así como por la denuncia social y política que hay en ellos, si bien me centraré especialmente en estos dos últimos, por cuestiones de espacio y por ser los más actuales a nuestro tiempo.

\footnotetext{
${ }^{1}$ Incluso ha servido el motivo de Ofelia a Federico García Lorca en su Romance sonámbulo. La gitana que ahí describe con su famoso "verde que te quiero verde" es una clara referencia a Ofelia, influencia de la lectura que Lorca hace de Shakespeare: "Fue sobre el agua verde de un oculto remanso, / en la puesta del sol de una tarde lejana” (IV, 466) Vid. García Montero, 2016.

${ }^{2}$ Véase las pinturas de Ofelia (1894) de John William Waterhouse; Ofelia (1852) de John Everett Millais; Ofelia (I883) de Alexandre Cabanel; El primer brote de locura de Ofelia (1864) de Dante Gabriel Rossetti; Ofelia / Pause for Thought (1870) de Pierre Auguste Cote; Ofelia de Ernest Hébert; Ophelia (I85I-53) y Ophelia (I863-64) de Arthur Hughes; Ophelia (1864) de George Frederic Watts.
} 


\section{Antecedentes}

Los motivos que empujan a una persona a cometer suicidio pueden ser muy variados y tener su origen en numerosas causas. El suicidio no solo produce efectos sobre la persona, también repercute en el entorno, a varios niveles, tanto en el círculo de conocidos íntimos como en la sociedad.

Ofelia se suicida, como ya sabemos, movida por la locura provocada por el conflicto entre sus intereses y los valores de la sociedad en la que vive. Con su suicidio, está realizando una crítica al sistema, con el que no se siente identificada ni cómoda (Seoane, 2015).

El suicidio tiene una larga tradición como forma de expresión y como herramienta de protesta política y social, desde la Antigüedad hasta nuestros días. La inmolación de Mohamed Bouazizi, un joven tunecino al que las autoridades requisaron su puesto de venta ambulante de fruta, provocó que las revueltas civiles en Túnez contra el dictador aumentaran, lo que desembocó en su huida del país (Crespo, 20II). Años antes, un monje budista vietnamita se suicidó prendiéndose fuego en una calle de la ciudad de Saigón, como acto de protesta por la cruenta represión que sufrían los practicantes del budismo a manos del gobierno de Ngo Dinh Diem (Parreño, 20l I).

Así pues, el suicidio de Ofelia puede ser entendido como un acto de rebelión contra la sociedad impuesta, por lo que no es de extrañar que se haya utilizado como medio para criticar la moral, la política y los valores de las sociedades a lo largo del tiempo. Tal es el caso de los poemas que expondré a continuación.

\section{I.I. Ophélie de Arthur Rimbaud}

Uno de los primeros autores que utilizan en su obra el motivo de Ofelia es Arthur Rimbaud. En su poema Ophélie, escrito en 1870, Rimbaud resalta la unión en armonía del cuerpo de la joven con la naturaleza, la belleza trágica que reside en su cuerpo, ya tranquilo. Deja atrás la idea del suicidio y del ahogamiento para centrarse en la calma de una Ofelia muerta que sigue la corriente del río y que se funde con la naturaleza, liberándose de las leyes del tiempo y quedando eternamente suspendida en la memoria del poeta, simbolizando la ruptura con una existencia de sufrimiento:

La blanche Ophélia flotte comme un grand lys,

Flotte très lentement, couchée en ses longs voiles...

- On entend dans les bois lointains des hallalis. (Rimbaud, 2016) 


\section{La lírica expresionista alemana}

Los poetas expresionistas rechazan la belleza como se había entendido hasta entonces y abrazan una nueva "estética de lo feo". Esta nueva estética impulsada por el Expresionismo encuentra sus máximos exponentes en los poetas Georg Heym y Gottfried Benn.

\section{I. Ophelia de Georg Heym.}

Georg Heym, con su poema Ophelia, escrito en 1910, explora la estetización de lo feo y el tema de la gran ciudad, siendo este, además, otro de los motivos recurrentes del Expresionismo.

El poema consta de dos partes diferenciadas: una primera donde prima la naturaleza y la estetización de lo feo, y otra donde se refleja el tema de la ciudad. Ambas partes están unidas a través del río que arrastra el cuerpo sin vida de Ofelia. En la primera parte predomina la naturaleza, los animales y la oscuridad.

El autor busca ofrecernos una imagen desagradable, pero acompañada de una extraña sensación de tranquilidad y armonía, donde ni siquiera importan los motivos de la muerte de la joven. La oscuridad de la selva da paso a la luz del entorno urbano, ofreciendo una visión colorida que exalta la vida y la libertad, comparando a Ofelia con un ave que alza el vuelo.

En las últimas estrofas aparece un paisaje industrial, característico del mundo moderno, en el que la naturaleza se ha dejado de lado y se han impuesto la técnica y el maquinismo. Se contraponen en el poema la calma y la paz de la muerte con la vida urbana, enérgica y explosiva.

El hundimiento definitivo de Ofelia en el agua simboliza el ocaso de la civilización actual (Maldonado Alemán, 2006: 83). En este poema se ha utilizado la figura de Ofelia como metáfora de la decadencia social. Ofelia se compara con la gran ciudad: ella ha muerto por su locura y flotará eternamente arrastrando un sufrimiento silencioso; la gran ciudad, con el ruido, las máquinas y la consecuente deshumanización, se desintegrará algún día, suponiendo también una muerte, metafórica o literal.

\subsection{Schöne Jugend de Gottfried Benn}

Gottfried Benn escribe el poema Schöne Jugend, perteneciente al ciclo Morgue und andere Gedichte (1912) que fue bien acogido por la vanguardia literaria, pero no tan bien recibido por la crítica tradicional, que lo consideró perverso y repugnante debido al placer manifestado hacia lo feo y desagradable.

Predomina en todo el poema un tono cínico y provocador, que impide cualquier alusión de belleza. Ya en el título Schöne Jugend ("Hermosa juventud") 
podemos ver el cinismo que prepondera durante todo el poema, pues hace referencia a una canción sentimental muy de moda en la época (Maldonado Alemán, 2006: 83)

Utilizando sus conocimientos como médico forense, Benn describe con precisión la anatomía del cuerpo sin vida de una joven, encontrado en un cañaveral. Ofelia es presentada así como un simple cadáver, no hay espacio para la belleza mientras describe su interior, salvo hacia las ratas, animales que por su naturaleza provoca desagrado en gran parte de la sociedad.

Aquí Ofelia, a diferencia del anterior poema, ya forma parte de la naturaleza, dando cobijo a otros seres, una familia de ratas que se han estado refugiando $y$ alimentando de la carne putrefacta de la muchacha. Es al final de la composición cuando comprendemos a quien se dirigía el título del poema: el poeta se lamenta de la muerte de las jóvenes ratas que habían anidado en el pecho de la mujer.

\section{Ofelia y lo político}

Tanto Bertolt Brecht como Peter Huchel son conocidos literatos comprometidos políticamente. Bertolt Brecht creó el teatro épico con el que, a través del efecto de distanciamiento o "extrañamiento", buscaba centrar su obra en las ideas y decisiones y no sumergir al público en un efecto catártico que le impidiera pensar por sí mismo, llevado por las emociones. Su intención era que, cuando el público abandonara las butacas y salieran por la puerta del teatro, no se sintieran iguales, sino conscientes de las injusticias y con ganas de cambiar el mundo (Monleón, 2012: 777-785). Por otra parte,

Peter Huchel se sintió a sí mismo como "una víctima de la división política de Alemania". Nació en Berlín, en 1903, en el seno de una familia de clase media. Pese a esto, su vida fue muy convulsa. Estudió Literatura y Filosofía y escribió, siempre fiel a una cosmovisión de izquierdas, su primer libro coincidiendo con el ascenso del nazismo. Más tarde se vería arrastrado por el escenario de la guerra, que tan bien refleja en sus poemas. Tras haber decidido abandonar el frente, fue apresado por el ejército soviético. Fue en la Alemania Oriental, es decir, la República Democrática Alemana (RDA), donde pudo cosechar los frutos de su trabajo intelectual, en la radio y como director de la revista literaria Sinn und form, que lideró hasta que las autoridades le dejaron. Quisieron imponerle un confinamiento en condiciones pésimas. Gracias al Pen Club y a la insistencia de los intelectuales occidentales se libró de ello. La lírica en la RDA sufrió tal represión que Huchel y otros poetas se vieron obligados a abandonarla, trasladándose a la RFA (Durzak, 2004: 399). 


\section{I. Bertolt Brecht: Ofelia y el asesinato de Rosa Luxemburg}

Durante su etapa de poeta expresionista, menos conocida que la de dramaturgo, Bertolt Brecht escribió varios poemas, de marcados tintes políticos, inspirándose en el motivo de Ofelia.

El 15 de enero de 1919 fue detenida Rosa Luxemburg y llevada, junto con Karl Liebknecht ${ }^{3}$, al Hotel Eden, donde recibió una paliza, además de insultos y humillaciones. Fue asesinada y lanzada al Landwehrkanal. Su cuerpo, ya putrefacto, no se descubrió hasta el 31 de mayo en una esclusa junto al aluvial formado ${ }^{4}$.

En el mismo año, curiosamente, Ballade von der roten Rosa, de Bertolt Brecht ${ }^{5}$, desaparece. No obstante, su amigo de la juventud Hans Otto Münsterer recuerda, unos años más tarde, los siguientes versos:

Die roten Fahnen der Revolution sind längst von den Dächtern herabgeweht...

Die rote Rosa schwamm als einzige Befreite. (Giese, 1993: 85) ${ }^{6}$

También la balada Vom ertrunkenen Mädchen, "de la mujer ahogada" parecía tener, en sus orígenes, conexión con el caso de Rosa Luxemburg, ya que al principio decía así: "Als sie erschlagen war und hinunterschwamm" ("Cuando fue asesinada y nadó hacia abajo"), pero más tarde, temiendo sus repercusiones políticas, lo modificó por "Als sie ertrunken war" (“Cuando murió ahogada”). Este poema transmite tranquilidad a través del clímax de la lentitud extrema del tiempo que evocan palabras como "lentamente", "frenaba”, “por fin”. El sentido poético y dulce lo vemos en "ópalo", “enredaban”, "acariciaban” y "estrellas”, pero también esto contrasta con lo repugnante, como en el poema de Heym, aunque aquí no se recurre a metáforas, sino que se dice explícitamente ("pudrirse", "cadáver"), lo que lo acerca un poco más al poema de Benn.

\footnotetext{
${ }^{3}$ Tanto Rosa Luxemburgo, teórica marxista de origen judío, como Karl Liebknecht, político comunista, son grandes símbolos marxistas, especialmente en Alemania. De hecho, todavía hoy, un domingo a mediados de enero, se celebra, cada año, en Berlín, el día de Rosa Luxemburgo y Karl Liebknecht, en recuerdo de su asesinato el I5 de enero de 1919. Vid. Negrete, 2014.

${ }^{4}$ Para más información vid. López, 2015.

${ }^{5}$ Tal fue la veneración de Bertolt Brecht por Rosa Luxemburg que escribió el siguiente epitafio en su memoria: "Aquí yace Rosa Luxemburg, una judía de Polonia, pionera de los trabajadores alemanes, asesinada en nombre de los opresores alemanes. ¡Los oprimidos entierran tu discordia!" (Lehmann 2016, traducción propia).

${ }^{6}$ Propuesta de traducción propia: "Las banderas rojas de la revolución / hace ya que dejaron de ondear desde los tejados. / La roja rosa / nadaba como la única liberada”.
} 
En la última estrofa se manifiesta que la joven es solo un cadáver, ya olvidado incluso por Dios. El autor trata el mismo tema que Benn: el anonimato del mundo moderno y el vacío existencial, pero desde un punto de vista más trágico, melancólico y triste al añadir la figura de Dios. Como ya escribió el mismo Brecht al final de su Hauspostille, en la poesía Gegen Verführung:

Laßt Euch nicht verführen!

Es gibt keine Wiederkehr.

\section{$[\ldots]$}

Ihr sterbt mit allen Tieren und es kommt nichts nachher. (Brecht, 1927: 87)

Se pone de manifiesto la visión anticristiana de Brecht en ambas poesías: “¡No os dejéis seducir! [...] ¡no hay nada después!”.

\subsection{El motivo político en Ophelia de Peter Huchel}

Más recientemente, en el año 1972, después de mudarse de la RDA a la RFA, Peter Huchel publicó la poesía Ophelia. La imagen central del poema reposa sobre "die schlammige Stachedrahtreuse" ("fangosa trampa de alambre de espino", que nos recuerda, sin duda, a "der schlamm'gen Tod" ('muddy death') de Shakespeare.

El paisaje son unas aguas fronterizas, donde los disparos y los gritos rompen con la calma de la naturaleza. Solo hay balas por todas partes y el paisaje fluvial ha perdido toda la paz y seguridad. Los muertos no pueden fluir libremente por las aguas y reintegrarse con la naturaleza, como habíamos visto en los poemas anteriores, sino que todos se agrupan al final en el alambre de espino, límite que los vivos tampoco pueden sobrepasar e incluso mueren allí cuando intentan sobrepasarlo.

Peter Huchel retoma con este poema los tintes políticos que inicialmente Brecht escribió en su poema de Ofelia y que acabó modificando. Plasma con una triste metáfora la frontera que existió desde 196I hasta 1989 entre los dos estados alemanes, y Ofelia es una víctima como tantas otras en ese momento. Su muerte equivale a la de todos aquellos que desean huir (Giese, 1993: 88). Es un tema que, precisamente por su actualidad, nos pone todavía los vellos de punta. Ofelia aquí podría equivaler también a la muerte de todos aquellos refugiados que se aventuran al mar en busca de una vida mejor.

${ }^{7}$ Traducción: "Contra la seducción". 


\section{Conclusiones}

La figura de Ofelia ha sido muy usada como motivo en la lírica expresionista alemana. Solo se han nombrado en este trabajo cuatro autores para poner de relieve las diferencias que existen a la hora de plasmar a Ofelia en un poema.

A pesar de que cada uno tiene sus peculiaridades, todos se influencian, directa $o$ indirectamente, del poema de Rimbaud y tienen en común la estetización de lo feo, ya sea de una manera más suave, como en el caso de Georg Heym, o de una manera más explícita, como hace Gottfried Benn, y son, además, una plasmación de la deshumanización que se vive en esta época. Incluso Peter Huchel, el más actual de los autores nombrados, también cumple con estas características.

Ofelia es la figura trágica que refleja la nueva concepción del mundo que estos poetas expresionistas perciben: un mundo en el que solo es posible encontrar la calma con la muerte. En todos los poemas hemos visto que la muerte y la consecuente integración del cuerpo de Ofelia en la naturaleza nos transmiten tranquilidad y serenidad, en cambio, el entorno se dibuja hostil cuando se habla de la gran ciudad, como en el poema de Heym.

Se trata de una lírica doblemente marginal, por la estética feísta que propulsa y por los temas que denuncia. La desazón, así como lo desagradable impregnan todos estos poemas, motivo por el cual, tal vez, la crítica no siempre los ha alabado. A día de hoy, aunque no constan dentro de ningún canon, los conservamos como un testimonio de una sociedad en la que desaparecía uno de sus pilares básicos: la humanidad.

\section{Referencias bibliográficas}

Bibliografia primaria

Benn, G. (1989), Gesammelte Werke in vier Bänden: Gedichte. Stuttgart: KlettCotta.

Brecht, B. (1927), Hauspostille. Frankfurt am Main: Suhrkamp.

Heym, G. (1964), Dichtungen. Stuttgart: Reclam.

Huchel, P. (1984), Gesammelte Werke Band I: Die Gedichte. Frankfurt am Main:

Suhrkamp.

Rimbaud, A. (20I6), Obra Completa Bilingüe. Vilaür: Atalanta.

Bibliografía secundaria

Durzak, M. (2004), "La división de la literatura alemana a partir de 1945" en Historia de la literatura. Volumen sexto. El Mundo Moderno: 1914 hasta nuestros días. Ediciones Akal. 
Crespo, M. (2011). Quemarse a lo bonzo: los orígenes de un desesperado acto de protesta | Mundo | elmundo.es. https://www.elmundo.es/elmundo/2011/01/21/internacional/1295626707.ht $\underline{\mathrm{ml}}$ (consulta 15/02/2020)

García Montero, L. (2016), Un lector llamado Federico García Lorca. Taurus.

Giese, P.C. (1963), Interpretationshilfen Lyrik des Expressionismus. Stuttgart: Klett.

Lehmann, H.T. (2016), Brecht lesen. Theater der Zeit.

López, M. (2015), “El canal que engulló la revolución”, La Vanguardia: http://www.lavanguardia.com/internacional/20150812/54434830717/canale ngullorevolucion.html (consulta 15/02/2020)

Maldonado Alemán, M. (2006), El Expresionismo y las vanguardias en la literatura alemana. Madrid: Síntesis.

Monleón, J. (2012). “El extrañamiento: un compromiso político”. Anales De La Literatura Española Contemporánea, 37(2), 777-785. Recuperado de: www.jstor.org/stable/23237391

Negrete, C. (2014), "La izquierda alemana homenajea la memoria de Rosa Luxemburgo”, El Diario:

http://www.eldiario.es/internacional/izquierdaalemana-homenajeaRosaLuxemburgo_0_216629148.html (consulta 15/02/2020)

Seoane, J. (2015). Suicidio y política. Encuentros en Psiquiatría. Conducta suicida, 1-19. Parreño, A. (2011). Mohamed Bouazizi, el hombre que prendió la mecha en Túnez - RTVE.es: https://www.rtve.es/noticias/20110123/mohamed-bouaziziheroe-iconorevolucion-tunecina/397339.shtml (consulta 15/02/2020). 
